\title{
Health care - an everlasting challenge in temporal and spatial domains
}

\author{
This article was published in the following Dove Press journal: \\ Journal of Multidisciplinary Healthcare \\ 30 September 2010 \\ Number of times this article has been viewed
}

\section{Wenxi Chen}

Biomedical Information Technology Laboratory, the University of Aizu, Aizu-Wakamatsu City, Fukushima, Japan
Correspondence:Wenxi Chen Biomedical Information Technology Laboratory, The University of Aizu Tsuruga, Ikki-machi, Aizu-Wakamatsu City, Fukushima, 965-8580 Japan

Email wenxi@u-aizu.ac.jp

\begin{abstract}
Health care is an everlasting challenge that requires effort at all levels, from national and organizational to individual domains, over a long-term period. This article reviews the historical development of health care-related issues worldwide and accentuates the necessity of health care in the current era. Through investigating the historical background in both the occidental and the oriental worlds and the latest achievements from academic and industrial endeavors, many lessons can be learnt, and as a result, an integrative strategy is proposed to meet today's pressing needs. A government-funded project, "Challenge to 100 years of age”, which involved more than 600 residents in west Aizu village, lasted over 15 years. After reviewing its outcomes, a metrology of health based upon the three-dimensional phase space, which integrates with social well-being, mental status, and physical condition for a lifelong span, is advocated as a measure of the holistic view of health state.
\end{abstract}

Keywords: triangle framework, metrology, holistic view, systematic review, health care worldwide, health care history

\section{Introduction}

On November 12 1990, Bill Gates delivered his keynote address entitled "Information at your fingertips" at Fall Comdex and depicted the promising future of the emerging information era. ${ }^{1}$ Nearly 20 years later, we are surrounded by an invisible computing environment and interconnected pervasively by either wired or wireless networks. We are already used to enjoying everything in our daily life conveniently, wherever we are. We benefit from online shopping and information exchange with people from the other side of the earth in an instant by just clicking the mouse on our desk. However, the mouse is likely a double-edged sword. Our lifestyle has changed dramatically, and we face many unprecedented problems in the health domain.

One of the greatest obsessions is the increase in chronic illness that has occurred concurrently with accompanying lifestyle changes. Figure 1 shows the change in mortality structure for different reasons, including diseases and natural decrepitude, over the past 100 years in Japan. Mortality due to conventional causes such as accidents, aging, hepatic disease, and pneumonia is under control, so there is no large change. Acute infectious diseases, such as tuberculosis, have disappeared completely since the 1980s. However, risks due to lifestyle-related chronic conditions are in an upsurge. The leading causes of death are cerebral disease, cardiovascular disease, and cancer, which account for $60 \%$ of all deaths.

The World Health Organization (WHO) also reported that chronic diseases are the leading causes of deaths worldwide and their impact is steadily growing. Approximately 


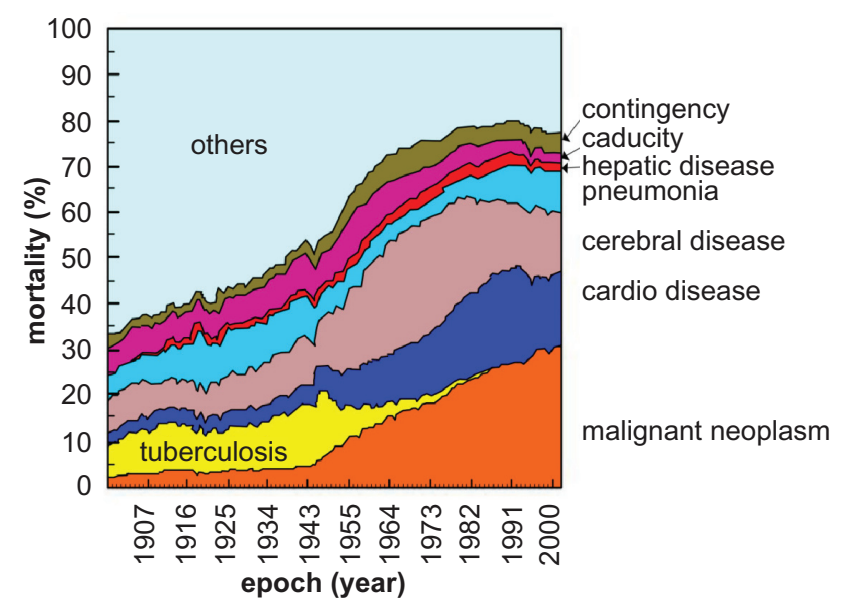

Figure I Change in mortality structure due to different reasons over the previous century in Japan.

Note: Drawn from data of the Japanese Ministry of Health, Labour, and Welfare.

17 million people die prematurely each year because of the global epidemic of chronic diseases. ${ }^{2}$ Today, health care, in relation to chronic conditions, is a more pressing challenge than ever before. To facilitate effective health care, an innovative strategy and action plan are required. Every country should consider health care as a long-term investment for future national dividend. They need to change policies in order to establish a stepwise framework for offering a flexible and practical public health care approach. They have to take steps toward discovering new knowledge and achieving significant improvements in prevention and control of chronic disease.

\section{Health care in the past}

Health care is neither a new desire nor a modish topic. Pursuing a healthier life and longevity through various means, using alchemies to discover the panacea, has been an ambition of human beings since ancient times.

Qin Shi Huang (259 BC to $210 \mathrm{BC}$ ), the first emperor of a unified China, mobilized national resources to pursue his dream of immortality in $219 \mathrm{BC}$. He dispatched a court sorcerer, $\mathrm{Xu} \mathrm{Fu}$, and his fleet, including 3,000 young men and women, to search for the elixir of life. ${ }^{3}$

An antiquity of the third century BC, known as the "Daoyin picture," shown in Figure 2, was unearthed in 1973 from a grave named "Mawangdui" in Hunan Province, China. ${ }^{4}$ It told a similar story of how health care among civilians dates back to the Han dynasty (206 BC to 220 AD) and was thought to be the earliest existing color painting concerning health care in Chinese history.

The painting illustrates 22 men and 22 women from different age groups on a piece of silk, $100 \mathrm{~cm}$ long and $50 \mathrm{~cm}$ high, showing 44 postures, such as squatting and kneeling, but most are in the standing position. Brief marginalia beside each posture indicate the action name and its effectiveness in preventing chronic conditions, such as arthritis, digestive system ailments, and problems with the sensory organs (eyes and ears) and immune system.

Daoyin exercise imitates the motion of animals, such as apes and monkeys, to stretch, incline, twist, rotate, and bend the limbs and trunk, as well as to play with sticks and balls. Such kinds of stretching and relaxing gymnastics aim to enhance cardiopulmonary function and improve health through various body and breathing movements (inhalation and exhalation, especially hypogastric breath).

Daoyin is academically accredited as being the root of Taijiquan and Qigong, both of which theories hold that

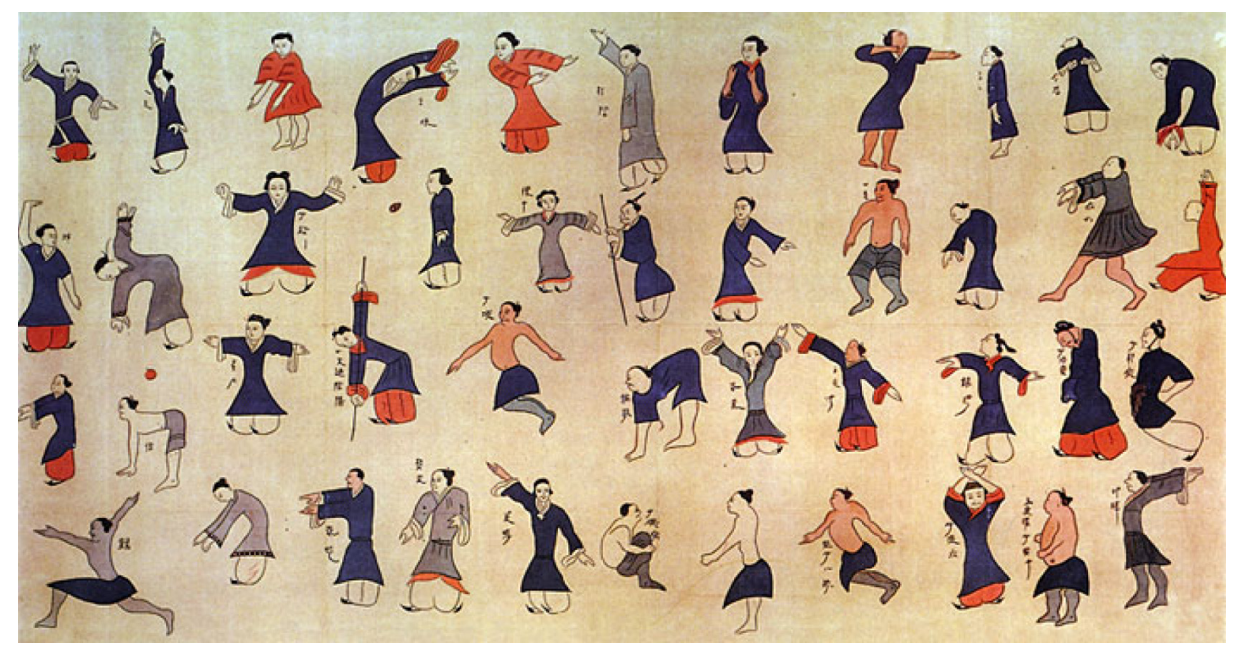

Figure 2 Daoyin gymnastic exercises depicting 44 persons in different postures on silk paper from more than 2000 years ago. Daoyin is a kind of stretching and relaxing gymnastics for health improvement and disease prevention. 
circulating Qi (subtle energy) through body movements can not only improve the health but also slow down the aging process and increase physical strength and mental acumen. ${ }^{5}$

In approximately the same historical period, around the second century BC, Maharishi Patanjali (there are no authentic records on his birth and death), an Indian philosopher known as "the Father of Yoga," compiled a collection of aphorisms on yoga practice in the book "the Yoga Sutra". These expressed his vision of "the oneness of human and nature". A healthy body and mind can be attained through the practice of relaxation, exercise, breathing, diet, and meditation, the so-called "Five Yoga Principles", by following the 8 stages in yoga in order to reunite with the divine energy in the universe. ${ }^{6}$

By synchronizing deep, slow, and rhythmic breathing with proper exercise through the yoga postures, or asana, can systematically stretch and tone the muscles and ligaments to help enhance the flexibility of the spine and the joints, improve blood circulation, and rejuvenate the various systems of the body.

As body and mind are intimately interconnected, meditation and physical relaxation can ease the tension in the muscles, rest the whole body, and in the end, help to conserve energy, revitalize bodily systems, achieve inner peace, and release worries and fears. Moreover, a well-balanced diet of natural foods nourishes both mind and body and keeps the body supple, the mind calm, and the immune system strong. Poor eating habits may result in ailments, such as obesity and diabetes.

Although only sages in ancient India practiced yoga, its benefits for both physical and mental health are widely recognized today.

Similarly, in ancient Greece, Herodicus (circa fifth century $\mathrm{BC}$; there are no authentic records of his birth and death), a gymnastics master, was respected as the father of sports medicine. ${ }^{7}$ He was credited with the first use of therapeutic exercise for the treatment of disease and the maintenance of health. $\mathrm{He}$ considered poor health to be the result of an imbalance between diet and physical activity, and therefore recommended a strict diet, regular physical activity, and massage using beneficial herbs and oils. Herodicus first laid down the principles for rational and mechanical methods of treatment and was one of the first to describe the technique of massage. He advised that movements should be slow and gentle at first, then rapid in combination with increased pressure, followed by gentle movements again. He believed that this combination was the ideal way to maintain good standards of health.

One of Herodicus' disciples, Hippocrates (circa 460 BC to circa $377 \mathrm{BC}$ ), who was considered the father of medicine, observed that some diseases were contracted by the manner of life and concluded that the constitutions and habits of people followed the nature of the land where they lived. He left the earliest definite information relating to the beneficial effects of massage and the general therapeutic application of mechanical vibration. Hippocrates suggested that applying massage with supplemental mechanical and physical processes is helpful to aid circulation, relieve stasis, and consequently, quicken metabolic processes. ${ }^{8}$

A rich variety of beliefs and practices were fostered over several millennia in the east and west based on distinct culture and philosophy. Through combining elements of qigong, yoga, meditation, massage, and martial arts to regulate breathing and mental activity, these finally evolved into hundreds of styles of medical sports and medical gymnastic exercises, which are widely used today to prevent disease and promote good health.

These ancestral heritages are our precious assets. "Standing on the shoulders of giants" enables us to fight diseases and manage health more wisely.

\section{Health care worldwide today}

The rapid changes in both societal environment and lifestyle threaten global health. Chronic conditions are now recognized as a compelling challenge to all of the communities rather than just a private matter. Although the risk of outbreaks, such as a new influenza pandemic, will require constant vigilance, it is the "invisible" epidemics of heart disease, stroke, diabetes, cancer, and other chronic diseases that, for the foreseeable future, will take the greatest toll in terms of deaths and disability. The WHO offers the health community a new global goal: to reduce death rates from all chronic diseases by $2 \%$ per year over and above the existing trends during the next 10 years. This global action to prevent chronic diseases would result in saving the lives of 36 million people who would otherwise have died due to chronic diseases by 2015 . The achievement would also result in appreciable economic benefits for all countries. ${ }^{2}$

A rapid response, above all, must be forward-looking. To raise all citizens' awareness of the importance of health promotion and disease prevention, the involvement of all areas of society and a creative approach are indispensable. A variety of policies, strategies, and activities are now being initiated nationwide in Japan at all levels, from administration and community groups down to the individual.

A 12-year government-sponsored campaign for health promotion, known as "Healthy Japan 21", has been advocated nationwide since the year $2000 .{ }^{9}$ In addition, the Japanese parliament ${ }^{10}$ issued a "health promotion law" to define individual 
responsibility and interactive coordination among citizens, communities, organizations, and government administrations. The law reconfirms that the national goal of medical insurance reconstruction is health promotion and disease prevention.

Founded in 2005, the Japan Mibyou System Association (JMSA) defined "mibyou" (hypohealth) as a state between health and disease. ${ }^{11}$ The JMSA is committed to the better control of the hypohealth state in order to improve human wellness. It has established a series of educational programmes and an official accreditation system for health promoters that aim to provide wholesome and secure care to all citizens.

More and more professional communities, research institutions, and industrial sectors across the world have been committing to daily health care. Many studies place high priority on personal lifelong health information infrastructure for the mass population in daily application.

The "Health Data Bank" application service provider service platform was released as a multifaceted aid for the management of corporate employee's medical examination results. ${ }^{12}$ The service supplies health care personnel with a set of tools for effective employee health guidance and counseling. It takes into account factors such as an employee's current physical condition, living habits, environment, and age-related changes in longitudinal management. Each employee can browse his or her personal data through internet channels and can view self-records of check-ups and graph detailing historical changes over a long period.

"Health Vault" is a universal hub of networks to connect personal health devices and other services. It helps to store and manage personal medical information in a single central site on the World Wide Web. ${ }^{13}$ It aims to provide a seamless connection interface for various home health and wellness monitoring devices, such as sport watches, blood glucose monitors, and blood pressure monitors, marketed by different manufacturers worldwide.

"Google Health" gathers personal medical records from doctors, hospitals, and pharmacies; manages medical history profiles, such as health conditions, medications, allergies, and laboratory results; and shares personal health information with family members, doctors, or caregivers. ${ }^{14}$

Philips proposed "the Complete Care Cycle" from prevention to telemedicine, aiming to cover paradigms of prevention, diagnosis, treatment, rehabilitation, and management. Its goal is to build a secure and personalized health care platform that provides a remote connection between chronically ill patients and their health care providers. It also aims to promote patients' behavior change, expand care providers' reach into homes, and improve clinical staff efficiency and effectiveness. ${ }^{15}$
To provide more effective vital sign monitoring suitable for daily use, a variety of pervasive computing technologies have been widely developed for health care applications.

Since the first accurate recording of an electrocardiogram (ECG) reported by Willem Einthoven in 1895, heartbeat measurement has come a long way and are now available for use in various situations. Whenever a person sits on a chair ${ }^{16}$ or on a toilet, ${ }^{17}$ sleeps in a bed, ${ }^{18,19}$ sits in a bathtub, ${ }^{20}$ or even takes a shower, ${ }^{21}$ the heartbeat can be monitored conveniently, without disturbing the person.

Over 50 home-oriented devices, such as pulse oximeters, ECG monitors, glucose monitors, insulin pumps, blood pressure monitors, spirometers, pedometers, body composition meters, and weight scales, have emerged in the personal health care market. Most of them are for both general wellness and chronic conditions, such as congestive heart failure, chronic obstructive pulmonary disorder, asthma, hypertension, diabetes, and obesity. Some of them include MedStar, ${ }^{22}$ Viterion Telehealth Life Center, ${ }^{23}$ Commander Home Monitor, ${ }^{24}$ Carematix Wellness System, ${ }^{25}$ LifeStar, ${ }^{26}$ Housecall Plus, ${ }^{27}$ MediCompass, ${ }^{28}$ SenseWear, ${ }^{29}$ HeartView, ${ }^{30}$ Motiva, ${ }^{31}$ Sentry Telehealth Monitor, ${ }^{32}$ Health Buddy, ${ }^{33}$ ViTelCare, ${ }^{34}$ Advanced care and alert portable telemedical MONitor, ${ }^{35}$ Wealthy outfit, ${ }^{36}$ and the Wellness phone. ${ }^{37}$

These products commonly characterize a home terminal connected to the internet or a telephone line and one or more wearable or portable devices that are able to measure various physiological data, such as body weight (BW), blood pressure, blood glucose, peak flow, oxygen saturation, heart rate and respiration rate, body fat and body temperature (BT), sleep, and energy expenditure.

A Canadian company, Care In Motion Technology Inc, has released an appealing solution called "Care in Motion". It includes distributed earphone-like devices and a central data server to provide a seamless health care service suitable for various daily life scenarios. Instead of using multiple disparate sensors, the earphone-like device adopts a unique scheme to monitor up to 20 physiological parameters, such as pulse rate, respiratory rate, $\mathrm{SpO}_{2}$, BT, sleep, and activity, continuously in real time. It is so small that it is promoted as "wear and forget". 38

Most current efforts are directed toward developing a series of pervasive vital sign monitoring technologies, such as "plug and play", "wear and forget", ${ }^{38}$ and "plug is all". ${ }^{18}$

However, an investigation from the WHO reported that most current health care systems still have common problems that need to be addressed: a) the difference between acute and chronic care is not sufficiently emphasized; b) patients are 
rarely supported by either a simple means of involving themselves in self-management or essential information to enable them to manage their condition to the greatest extent possible; c) patients are seldom provided with a long-term management plan for chronic conditions to ensure the best outcomes. ${ }^{39}$

Such problems remain to be solved by a systematic scheme. This system should stress several aspects in 1) how to facilitate physiological data collection seamlessly and persistently in the daily environment, 2) how to apply data mining algorithms to perform comprehensive interpretation of multifarious long-term data fusion, and ultimately, 3) how to build a scalable health care integrated platform for individualized lifelong health management. ${ }^{40}$

\section{The "Challenge to I 00 years of age" project in west Aizu village}

Since 1994, west Aizu village had pioneered the "Challenge to 100 years of age" project, with public financial support of circa $¥ 2.4$ billion (US $\$ 28.13$ million). ${ }^{41}$ The fundamental goal is to promote healthier life and longevity by providing a total care solution package to villagers. The village built a wired network infrastructure, improved the soil, delivered enhanced educational programs on the importance of a nutritionally balanced diet and good lifestyle practices, and initiated a health promotion campaign. Homecare devices were distributed to 687 of 2,819 families in the village. The device can measure systolic blood pressure (SBP), diastolic blood pressure (DBP), $\mathrm{BT}$, and $\mathrm{BW}$; record a one-minute ECG and heart rate (HR); and collect answers to a daily questionnaire shown on a liquid crystal display screen. The time of the daily measurement is not strictly stipulated: either morning or afternoon is fine, depending on the users' preference. Data are transmitted to the health care centre from home network. Seven health care nurses are in charge of the data analysis and responses to inquiries from users. Biochemical markers from blood and urine samples are also collected once a year.

Figure 3 shows 2 data samples measured during a 2-year period from a couple; a) and b) indicate the wife and husband, respectively. It is observed that the temporal structure of vital signs in the wife demonstrates the wax and wane corresponding to the seasonal ebb and flow. SBP, DBP, and HR tend to decline in the summer and rise in the winter. However, the seasonal biorhythmicity in the husband shows a different pattern. By analyzing the data collected from hundreds of persons over several years, it is found that individual biorhythmicity differs in period and mesor, amplitude and phase, and zenith and nadir. Comprehensive interpretation and proper visualization of these data from different standpoints are relevant to users' pathophysiological conditions, health state (HS), and longevity.

Figure 4 represents a demonstration of data visualization in a transformed space, which illustrates the monthly change in the SBP profile over 2 years. The reference profile for comparison is obtained by averaging 24 monthly SBP profiles. Monthly change is evaluated by calculating the similarity between a monthly profile and the reference profile using the dynamic time warping (DTW) method. ${ }^{42}$ Results are derived using the data shown in Figures $3 \mathrm{~A}$ and $3 \mathrm{~B}$, respectively.

Comparing the remarkable rhythmic alternations in Figure 3A, only smaller changes in the monthly SBP profile can be seen in Figure 4A. On the contrary, the indistinctive seasonal fluctuation in Figure 3B exhibits a larger diversity among monthly repetitive patterns in Figure 4B.

The outcomes yielded by the above endeavors are striking. Demographic investigation and epidemiological analysis show that the villagers' longevity increased from 73.1 years (80.0 years for females) in 1985 to 77.6 years (84.1 years for females) in 2000, and mortality from stomach cancer decreased from $138.9 \%$ (125.4\% for females) in 1988 to $91.7 \%(66.7 \%$ for females) in 2002 referring to national average as $100 \%{ }^{41}$

More insights into the outcomes of the causalities among many relevant factors are likely to be obtained by further mining this mountain of data and will be reported in separate papers. Still, many questions, such as how to make sense of these results obtained from analyzing huge amounts of collected data, how to infer a person's HS based on these results, and how to predict the future propensity to HS based on the current and past health conditions, remain to be answered. Study in these domains relies on proper mathematical approaches and data fusion models, which will perhaps require an appropriate definition of health and establishment of a new discipline for quantifying the HS comprehensively.

\section{Metrology of health}

HS is a changing dynamic condition throughout life. Metrology of health aims to quantify the overall HS from an integrative standpoint. ${ }^{43}$ Health evaluation was conventionally conducted by demographic investigation and epidemiological analysis based on large population data accumulated over a long period. In this way, a statistical confidence interval for discriminating between healthy and unhealthy was determined. On the other hand, the definition of health from the WHO advocates that, "health is a state of complete physical, mental and social well-being and not merely the absence of disease or infirmity". ${ }^{44}$ This is commonly referred to as "the Health Triangle". 

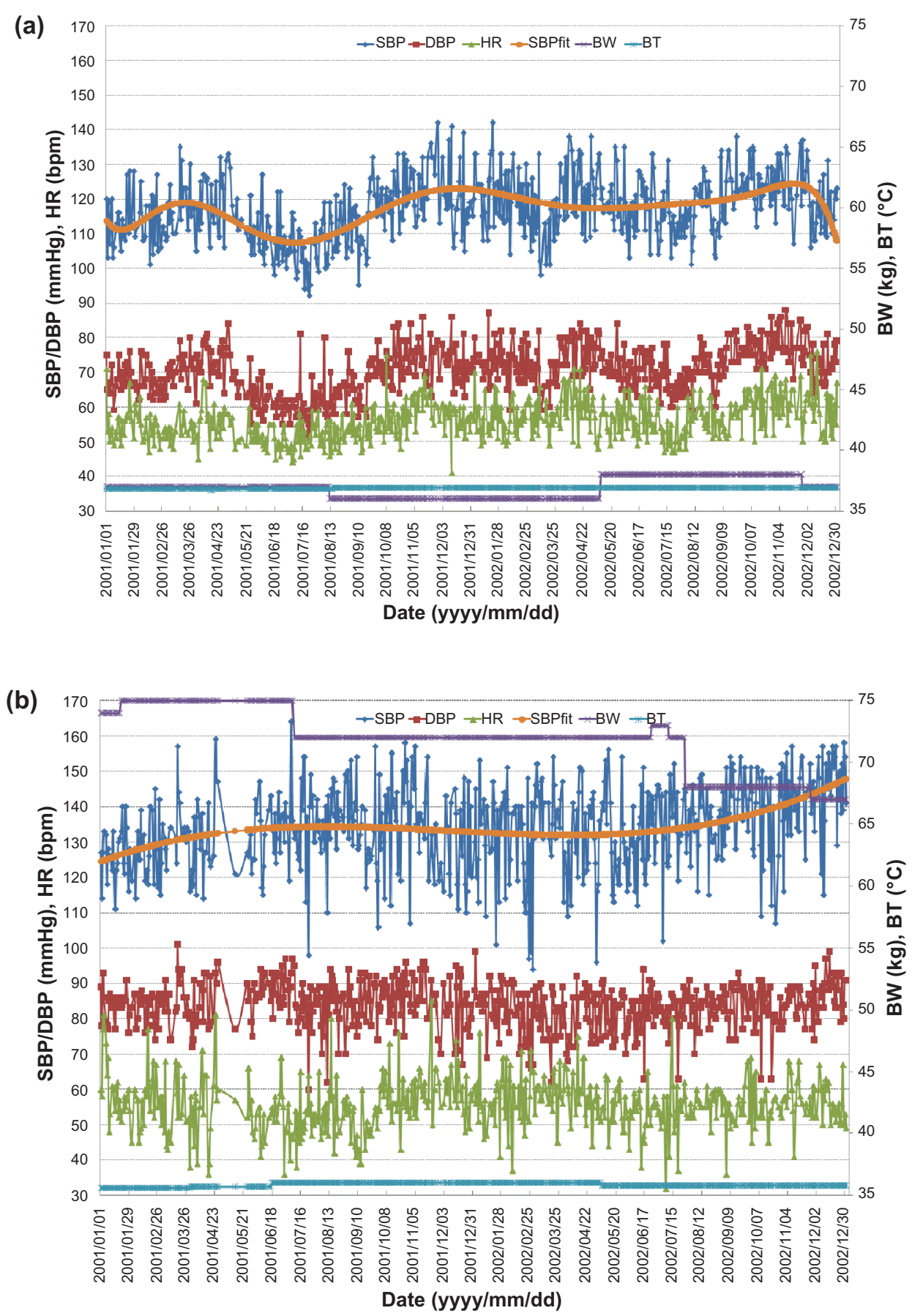

Figure 3 Profiles of daily HR, SBP, DBP, BT, and BW data collected from a couple ([a] wife, age 84 and [b] husband, age 85) over a 2-year period. Sporadic blanks indicate no measurement on those days. The bold solid lines are the polynomial approximation of SBP (9th order for [a] and 3rd order for [b]). Most data were measured in the afternoon.

Abbreviations: SBP, systolic blood pressure; DBP, diastolic blood pressure; HR, heart rate; BW, body weight; BT, body temperature.

A three-dimensional (3D) phase space is proposed to express the changing HS over a lifetime, as shown in Figure 5. The 3 dimensions are physical condition ( $\mathrm{x}$-axis), mental status (y-axis), and social well-being (z-axis). An individual lifelong health dynamics is described by a unique locus in the phase space continuum.
The space continuum is divided into 5 spheriform regions indicating 5 HSs: inactive (blue), healthy (green), hypohealthy (yellow), unhealthy (red), and infinite (white). The boundaries of zones vary and depend on individual adaptation and longterm evolution. The blue zone indicates the inactive or unconscious state, such as a baby in infancy or an elder in senile 


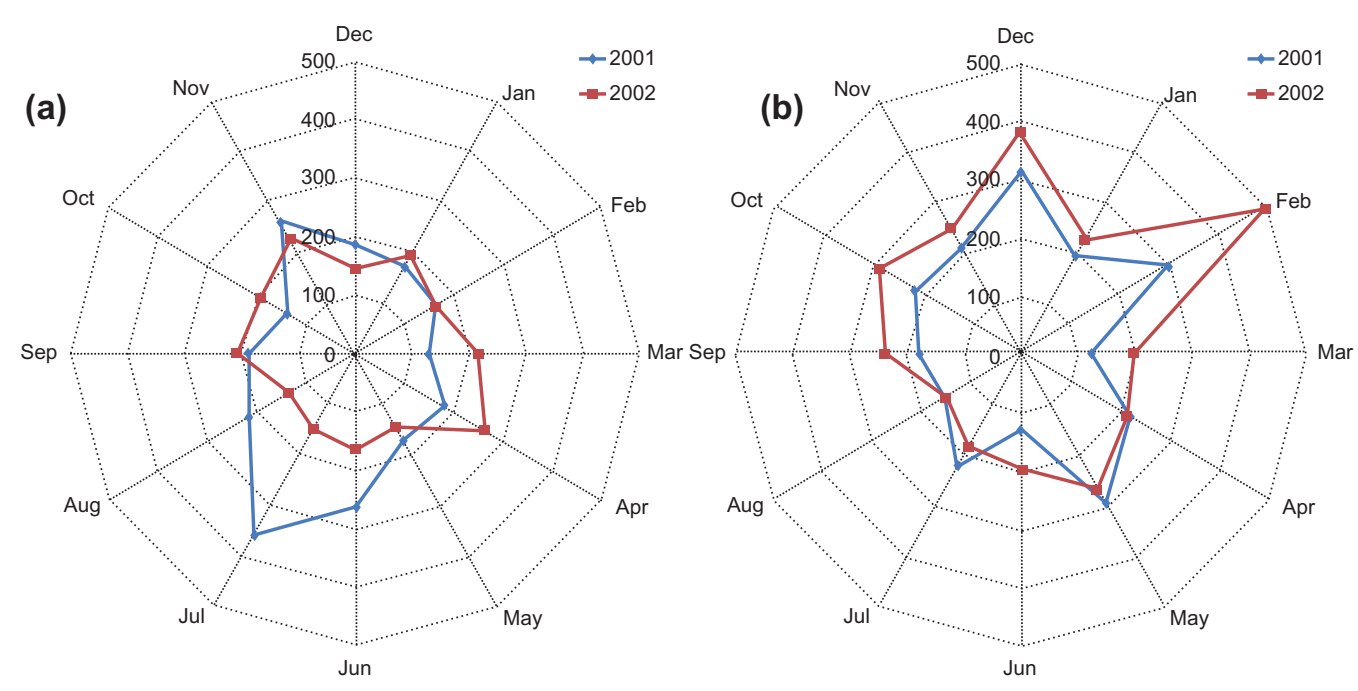

Figure 4 Similarity analysis of the monthly change in the SBP profile by the DTW method. A smaller value indicates a larger similarity with the reference profile. Monthly change in similarity is plotted clockwise from January $200 \mathrm{I}$ to December 2002.

Abbreviations: SBP, systolic blood pressure; DTW, dynamic time warping.

dementia or a feeble state. The green zone is a state in which the overall function in all aspects works properly. The yellow zone represents a hypohealthy state between healthy and morbid states. It can easily be ameliorated to a healthy state when treated earlier, but can possibly deteriorate to an unhealthy state if left untreated. The red zone indicates an unhealthy or morbid state, from which one is able to either recover to hypohealthy or deteriorate to death. The white zone indicates an emanative or infinite state where life has ceased irrecoverably.

HS dynamics over the course of a life is described as a continuous trace in the $3 \mathrm{D}$ space continuum unless interrupted by a paroxysmal event, such as a traffic accident, a natural disaster, or a murder. Each point in the space indicates a HS at a temporal moment. A person's HS is mostly located in the green zone, with an occasional aberration to yellow, and even the red zone if he or she falls sick.

Every life is created from a fertilized ovum through a programmed cellular division, but no two bodily existences exhibit identical patterns. Each life begins at the origin, but then grows at different initial speed in diverse directions in the space continuum.

However, death, as a destination of the life course, is much more complicated. Death may be caused by bodily functions ceasing because of the natural caducity or cytoclasis or due to an accident or other cause leading to sudden death. From the standpoint of the health metrology framework, demise due to natural aging without disease is an ideal life process, which is expressed as converging to the origin as shown in Figure 5A. If
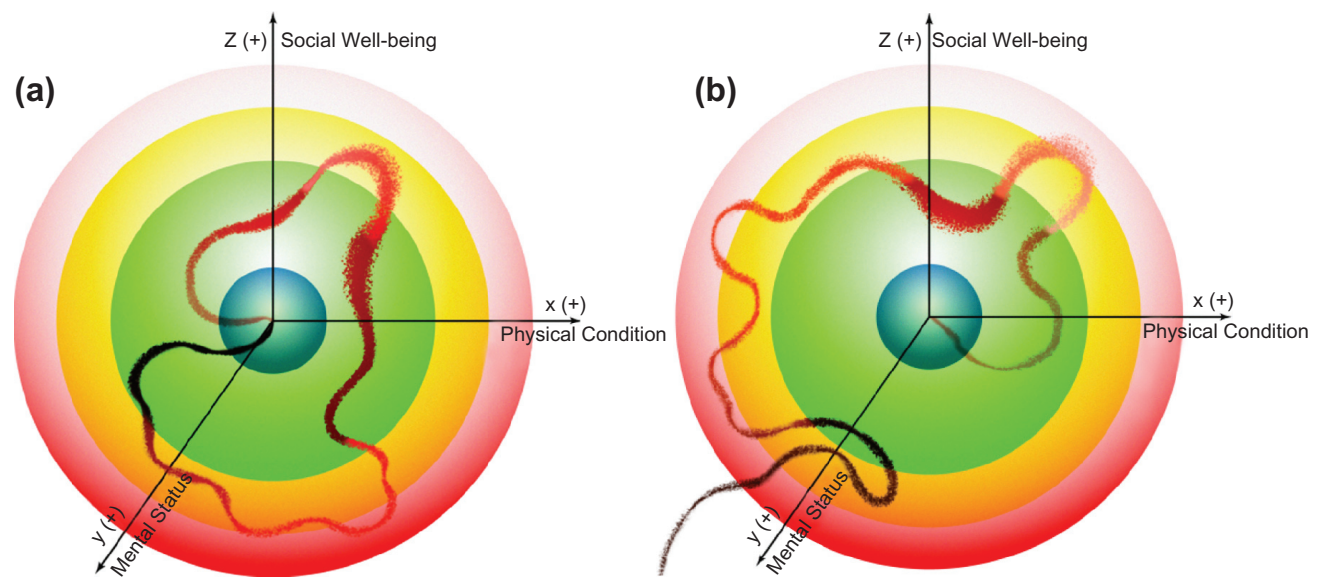

Figure $5 \mathrm{~A}$ 3D view in the phase space of health state. A lifelong course of health state dynamics, from birth to death crossing different zones, is illustrated. a) indicates a case in which life ceases because of the natural decrepitude. b) indicates a case in which the person succumbs to death due to the disease. 
death is due to accident or disease, the trace will diverge in the infinite, as shown in Figure 5B. The difference is that the former will be continuous, while the latter would have discontinuity.

The physical condition of a human body can now be investigated on multiple scales, from molecules to cells, through tissues and organs, up to the whole body. Mathematical model simulation from the microscale to the macroscale for the biological continuum provides a systematic framework for interpreting the wealth of findings obtained from biological, physiological, and clinical research. Various instrumentation techniques can detect and quantify organic lesions by investigating various biomarkers and physiological signs. Moreover, mathematical models can simulate pathophysiological processes and predict how and when diseases will develop..$^{45,46}$

Mental status describes a level of either cognitive or emotional health and is clinically assessed by mental status examination through a Mental Status Exam (MSE) form in psychiatric practice. ${ }^{47}$ The MSE form includes 12 items (appearance, attitude, behavior, speech, affect, mood, thought processes, thought content, perception, orientation, memory/concentration, insight/judgment) to observe and aims to quantify a person's current state of mind. The MSE is actually a blend of empathic descriptive phenomenology and empirical clinical observation. Objective descriptions of a person's mental status are now supported by interpreting neurophysiological evidence from advanced neuropsychiatric diagnostic tools, such as positron emission tomography and magnetic resonance imaging. ${ }^{48}$

The term social well-being has been used mainly in sociology studies and involves particularly complicated issues. Many attempts have been made to quantify social well-being by a numerical measure. Indicators, such as public and private consumption per head; income level; unemployment rate; infant survival rate; life expectancy at birth; accessibility to social, medical, and educational services; and quality of life, are usually used to measure social well-being, to evaluate economic activity and living standard, and to develop better economic policies. ${ }^{49}$

On the other hand, social well-being in the Health Triangle framework should describe personality from the point of view of social interconnection, personal contribution, and the ability to function in social activities. ${ }^{50}$ It must include some features pertaining to personal characteristics, such as social credits (SC), eg, credit card and tax payment records, police files, and public reputation (PR) from the surroundings.

It is well known that, as a general rule, physical ailments, mental disorders, and social malfunctions are interconnected.
An unhealthy body can trigger an unhealthy mind, and mental disorder can worsen diseases in the body and lead to malfunction in social activity. Fixing a problem in one area can often help the others.

In summary, HS is a function $h(x, y, z)$ of collective factors in 3 dimensions.

$$
\mathrm{HS}=h(x, y, z)
$$

where $x, y$, and $z$ are the coordinates in the $3 \mathrm{D}$ phase space and can be further expressed as given below.

$$
\begin{gathered}
x=f_{x}\left[\operatorname{HR}(t), \operatorname{BP}(t), \mathrm{BT}(t), \ldots, \mathrm{EF}_{x}(t), \mathrm{IC}_{x y z}(t)\right] \\
y=f_{y}\left[\operatorname{MSE}(t), \ldots, \mathrm{EF}_{y}(t), \mathrm{IC}_{y x z}(t)\right] \\
z=f_{z}\left[\operatorname{SC}(t), \operatorname{PR}(t), \ldots, \mathrm{EF}_{z}(t), \mathrm{IC}_{z x y}(t)\right]
\end{gathered}
$$

The terms $E F(t)$ and $I C(t)$ describe the environmental factors and the interconnection among the 3 dimensions, respectively.

Modern chaos theory has been applied to a wide variety of biological phenomena. ${ }^{51}$ Deterministic behavior characterizes chaos, where irregular patterns obey mathematical equations and are critically dependent on initial conditions. Little disparity in the initial condition can lead to an entirely different trajectory in the phase space. ${ }^{52}$

In the Health Triangle framework, all possible states in the phase space can be described as a chaotic function of time showing the health dynamics in various zones. Each dot indicates a HS in a time moment. Cloud-like dot clusters illustrate the health dynamics with focal stability and random perturbation. During the juvenile and teenage phases, variation may be larger and recovery is generally faster. In contrast, from middle age, fluctuations become smaller and recovery is usually slower. A succession of clustered dots describes the HS evolving over time. Its shape and demeanor elucidate life dynamics in terms of HS over a lifelong course from birth to death. The above description aims to substantiate the Health Triangle concept. Further quantitative exploration on the metrology of health is open to the health care communities for extensive discussion and intense collaborations among multiple disciplines.

\section{Discussion}

From the ancient Greek philosophers, like Plato (circa 429 BC to circa $347 \mathrm{BC}$ ) and Aristotle (circa $384 \mathrm{BC}$ to circa $322 \mathrm{BC}$ ), to German philosopher, Georg Wilhelm Friedrich Hegel (1770-1831), one statement continues to reverberate; "What is rational is actual, and what is actual is rational". Despite 2-400 million sperms are released in a single ejaculation to travel along the female's vagina through the cervix and the 
uterus to meet a mature ovum, only 1 sperm can fertilize this ovum, creating a unique new life. Although the preventative mechanisms of polyspermy are believed to be essential in inhibiting fertilization by more than 1 sperm, additional details concerning changes in the zona pellucida remain unknown. ${ }^{53}$ Nevertheless, we can imagine how fierce the competition is among the sperms in the uterus. Still, it cannot be concluded that the successful sperm is the strongest among all the competitors, like a marathon winner, but it seems that there is no doubt that this unique new life must be created most adaptively and optimally among all possible options from the point of view of natural selection and evolution.

Because the process of natural selection and evolution shapes most of the vulnerabilities in organisms, disease is considered inevitable yet an effective protection mechanism in the human body, responding to hostile factors in order to render the body immune from further harm. ${ }^{54}$

Ancient wisdom pointed out that diseases arise from either a lack or surfeit of use of the body. ${ }^{55}$ It implies that when a body is kept operating within the proper range of self-adjustment and adaptability, the body works steadily and can recover from ailments via its intrinsic defense mechanisms. If it is forced to work outside its proper range, illness follows.

Many illnesses, including mental disorders and physical diseases, and especially lifestyle-related chronic conditions, such as hypertension, hyperlipidemia, diabetes, obesity, arteriosclerosis, osteoporosis, asymptomatic stroke, potential heart attack, and fatty liver are due to years of bodily abuse and mental overstress.

Traditional Chinese medicine (TCM) considers that human moods, health, and behavior are modulated by the ebb and flow of yin and yang, and an imbalance between the yin and yang states is the essential cause of the incidence and exacerbation of a disease. The goal of treatment is, in principle, to restore and maintain the balance between yin and yang among the visceral organs. ${ }^{55}$ Similarly, ancient western medicine claims that health is the equal distribution of the forces from moist, dry, cold, hot, bitter, sweet, and so on. Dominance of any one of these would be destructive and lead to disease. Health, by contrast, is a harmonious blending of these factors. ${ }^{56}$ Recent medicinal studies show that modern epidemics are most likely to arise from the mismatch between the physiological design of our bodies and novel aspects of our environment. ${ }^{54}$ Acute and chronic conditions manifest through different mechanisms and over varying time spans, and therefore the approach to deal with each should be different.

Bian Que (407 BC to 310 BC) was a famous Chinese physician during the period of warring states in China. When the
King of the feudal state of Wei asked him, "You and your two brothers are all skilled in medicine, which of you is the best?" Bian Que answered, "My eldest brother is the best, second brother is the next, and I am the last." The King puzzled and asked, "Then how is it that you are the most famous?" Bian Que replied, "My eldest brother takes care of persons before they feel any symptoms, my second brother cures diseases in their early stage. People thus mistake them as not special or only capable of treating minor ailments, while I treat diseases when they are already well developed or are very serious. People therefore look upon me as well versed in medical skill, and know my fame all over the country". ${ }^{57,58}$

The prevention of disease is of primary importance in TCM doctrine and practice. It insists that a highly skilled doctor usually focuses on preventing the incidence of diseases instead of treating diseases, just as a wise monarch governs his country by satisfying his citizens rather than suppressing their probable riot before they feel desperation. This is simply metaphorized that we should avoid digging a well after feeling thirsty or forging weapons after war has begun. ${ }^{55}$

A dualism that considered mind and body separately prevailed until René Déscartes in the 17th century. Over the past few decades, researchers have conducted hundreds of scientific studies in an attempt to measure the effects of spirituality on health from a holistic point of view. Researchers have come to understand that mental state and physical condition are intimately connected. A weakened body can lead to a frazzled mind, whereas depression can trigger or worsen diseases in the body. Fixing a problem in one aspect, moreover, can often help the other. ${ }^{59}$ Nevertheless, we still know very little about spirituality, although it performs potently, because its measurement is often beyond the scope of current scientific research. Moreover, health is usually improved slowly through daily activities conducted on a regular basis, and many significant benefits of improved health may have no obvious signs within a short term. This common dilemma colors the public view of the scientific validity of such approach.

Although meditation cannot manifest significantly the slow cancer growth or improve recovery from acute illness, one of the clearest health benefits of churchgoers is that they live longer than nonattendees. In other words, churchgoers have a $25 \%$ reduction in mortality. ${ }^{60}$ Mysteries such as why some people are vulnerable and others are not, and why spirituality has different effects on different persons and different diseases remain a puzzle.

Even if religion and spirituality were shown convincingly to be related to better health, some critics briefly analyzed 
many studies assessing the effects of church attendances and prayers on health and asserted that those studies fail to control for factors such as behavioral and genetic differences, age, sex, education, and HS. They concluded that the evidence of an association between spirituality and health is weak and lacks consistency, even among well-conducted studies. It is still premature to promote faith and religion as adjunctive medical treatments. ${ }^{61,62}$ Because contradictory conclusions from the large amount of data collected using different experimental protocols and interpreted using various methods often confuse rather than clarifying the issue, establishment of a metrological theory to evaluate the HS systematically is invaluable.

Two of the most important goals in the metrology of health are to quantify the personal HS through comprehensive interpretation of multifarious data collected over a period of years in the Health Triangle framework and to untangle the causal connections among longevity and biorhythmicities; pathogeny and immunity; temporal and environmental factors; and social, behavioral, and psychoneurotic aspects. A lifelong health information infrastructure and systematic methodology will serve these ends.

\section{Conclusion}

As long as life on earth continues, health care is an everlasting challenge affecting the sustainable development and prosperity of human beings in the future and no longer just a personal matter. It is a colligational issue and requires total commitment at all levels.

Aging is a trade-off mechanism to avoid further harm from diseases. Immortality is impossible biologically because all the biological systems have the apoptosis mechanism genetically built-in. However, we can strive to conduct a healthier life, to slow down the aging process, and to live longer.

Health care is an effective way to prevent and control chronic diseases and has emerged as a key part of a growing global awareness of the need for significant investments of time, enthusiasm, and money. The paradigm must shift from an intermittent hospitalbased system to a lifelong home-based scheme, where every home should be a hub for health care deployment in order for individuals to be involved on a daily basis in an entire care cycle from prevention to diagnosis and from treatment to follow-up.

There are a bundle of compromises among multiple causalities in health amelioration. Although an omnipotent elixir enabling all people to recover from disease and maintain good health does not exist, rhythmic daily lifestyle, intake of nutritionally balanced meals, daily exercise, positive attitude, and mental wellness should be elements of a common formula. Just as diseases need time to breed, good health needs not only time to cultivate but also time to maintain. Time may be the best recipe for all people, both philosophically and mundanely.

\section{Epilogue}

On the coming November 9 at the 2010 mHealth Summit, 20 years later after his speech "Information at your fingertips", Bill Gates will be presenting a keynote address to discuss how modern information and communication technologies can save lives and promote health by connecting leaders in industry, government, academia, philanthropic organizations and the private sector. $^{63}$ In 20 years' time, November 6 2030, what further surprises will Bill Gates have brought to the world?

\section{Acknowledgments}

The author thanks Mr Satoru Ohtake and Mr Hirokazu Muto of the villagers' information division, Ms Sachie Nitta of the health centre in west Aizu for their assistance, his graduate student Mr Hiroo Watanabe for data analysis, and the participants of the project for data collection over the years.

This study was supported financially in part by Ministry of Education, Culture, Sports, Science and Technology (MEXT) Grants-In-Aid for Scientific Research No. 20500601 and the University of Aizu Competitive Research Funding P-32. Study in section 4 was conducted under a cooperative agreement between the University of Aizu and west Aizu village, described in the section "Challenge to 100 years of age".

\section{Disclosure}

The author reports no conflicts of interest in this work.

\section{References}

1. Microsoft Corp. Available from: http://channel9.msdn.com/shows/ history/the-history-of-microsoft-1990. Accessed Sept 1, 2010.

2. WHO. Available from: http://www.searo.who.int/en/section1174/ section1459_10496.htm. Accessed Sept 1, 2010.

3. Sima Q, (109 BC to $91 \mathrm{BC}$ ). Records of the Grand Historian (Shiji); vol. 6 and 18. Beijing: Zhonghua Book Company; 1982.

4. "Mawangdui" grave. Available from: http://www.hnmuseum.com/ hnmuseum/whatson/exhibition/mwd.jsp. Accessed Sept 1, 2010.

5. Li W. Introduction to Qigong and Taijiquan. Nanjing: Jiangsu Science and Technology Publishing House; 1985.

6. Yoga. Available from: http://en.wikipedia.org/wiki/Yoga. Accessed Sept $1,2010$.

7. Georgoulis AD, Kiapidou IS, Velogianni L, Stergiou N, Boland A. Herodicus, the father of sports medicine. Knee Surg Sports Traumatol Arthrosc. 2007;15:315-318.

8. Lloyd GER. Hippocratic Writings, editor Chadwick J, translator. London: Penguin Classics; 1984.

9. Japan Health Promotion and Fitness Foundation, Healthy Japan 21, Available from: http://www.kenkounippon21.gr.jp. Accessed Sept 1, 2010.

10. Japanese Ministry of Health, Labour and Welfare. Health promotion law. Available from: http://www.ron.gr.jp/law/law/kenko_zo.htm. Accessed Sept $1,2010$.

11. Japan Mibyou System Association. Available from: http://www.mibyou. gr.jp/. Accessed Sept 1, 2010.

12. NTT Data Corp. Health Data Bank. Available from: http://www.nttdata. co.jp/en/media/2002/080101.html. Accessed Sept 1, 2010.

13. Microsoft Corp. Available from: http://www.healthvault.com/. Accessed Sept 1,2010.

14. Google Corp. Available from: http://www.google.com/intl/ja/health/ tour/. Accessed Sept 1, 2010. 
15. Philips Electronics. Available from: http://www.healthcare.philips.com/ main/index.wpd. Accessed Sept 1, 2010.

16. Lim YG, Kim KK, Park KS. ECG measurement on a chair without conductive contact. IEEE Trans Biomed Eng. 2006;53(5):956-959.

17. Togawa T, Tamura T, Zhou J, Mizukami H, Ishijima M. Physiological monitoring systems attached to the bed and sanitary equipments. In: Proceedings of the Annual International Conference of the IEEE Engineering in Medicine and Biology Society. 1989;5:1461-1463.

18. Chen W, Zhu X, Nemoto T, KanemitsuY, Kitamura K, Yamakoshi K. Unconstrained detection of respiration rhythm and pulse rate with one under-pillow sensor during sleep. Med Biol Eng Comput. 2005;43(2): 306-312.

19. Kawarada A, Nambu M, Tamura T, Ishijima M, Yamakoshi K, Togawa T. Fully automated monitoring system of health status in daily life. In: Proceedings of the 22nd Annual International Conference of the IEEE Engineering in Medicine and Biology Society. 2000;1:531-533.

20. Tamura T, Yoshimura T, Nakajima K, Miike H, Togawa T. Unconstrained heart-rate monitoring during bathing. Biomed Instrum Technol. 1997;31(4):391-396.

21. Fujii M, Dema H, Ueda T, inventors; Cybernet Medical Corp, assignee. Liquid jet electrode and surface potential detector. Japanese patent JP2002-65625A. Mar 5, 2002.

22. Cybernet Medical Corp. Available from: http://www.cybernetmedical. com/. Accessed Sept 1, 2010.

23. Viterion TeleHealthcare. Available from: http://www.viterion.com/ Accessed Sept 1, 2010.

24. Cardiocom. Available from: http://www.cardiocom.com/. Accessed Sept $1,2010$.

25. Carematrix. Available from: http://www.carematrix.com/. Accessed Sept 1, 2010.

26. LifeWatch Corp. Available from: http://www.lifewatch.com/. Accessed Sept 1, 2010.

27. Mednet Healthcare Technologies Inc. Available from: http://www. mednethealth.net/. Accessed Sept 1, 2010.

28. iMetrikus Inc. Available from: http://www.imetrikus.com/. Accessed Sept 1, 2010

29. Body Media. Available from: http://www.bodymedia.com/. Accessed Sept 1, 2010.

30. Aerotel Medical Systems Ltd. Available from: http:/www.aerotel.com/. Accessed Sept 1, 2010.

31. Philips. Available from: http://www.healthcare.philips.com/main/ products/telehealth/Products/motiva.wpd. Accessed Sept 1, 2010.

32. Honeywell HomMed. Available from: http://www.hommed.com/. Accessed Sept 1, 2010.

33. Health Buddy. Available from: http://www.healthbuddy.com/. Accessed Sept 1, 2010.

34. Visual Telecommunications Network Inc. Available from: http://www. vitelnet.com/. Accessed Sept 1, 2010.

35. Anliker U, Ward JA, Lukowicz P, et al. AMON: a wearable multiparameter medical monitoring and alert system. IEEE Trans Inf Technol Biomed. 2004;8(4):415-427.

36. Marculescu D, Marculescu R, Park S, Jayaraman S. Ready to wear. In: Spectrum, IEEE. 2003;40(10):28-32.

37. Sharp Corp. Wellness mobile phone. Available from: http://plusd.itmedia. co.jp/mobile/articles/0805/27/news064.html. Accessed Sept 1, 2010.

38. CIM technology Inc. Available from: http://www.cim-t.net/. Accessed Sept 1, 2010.

39. WHO. A Long-Term Care Futures Tool-Kit, Pilot edition. 2002.
40. Chen W, Zhu X, Nemoto T, Wei D, Togawa T. A scalable healthcare integrated platform (SHIP) and key technologies for daily application. In: Giannopoulou EG editor. Data Mining in Medical and Biological Research. Vienna: IN-TECH Publishing House; 2008: 177-208.

41. West Aizu. Challenge to 100 Years of Age - The Making of a Healthy Village through a Total Care Solution. Fukushima: Zaikai21 Publishing House; 2003.

42. Salvador $\mathrm{S}$, Chan P. Toward accurate dynamic time warping in linear time and space. Intell Data Anal. 2007;11(5):561-580.

43. Yamamoto S. Metrology of Health. Tokyo: Asakura Publishing House; 1993.

44. WHO. Official Records of the World Health Organization. Preamble to the Constitution of the World Health Organization. NY, 1946 Jun 19-22; WHO, vol 2, p. 100.

45. White R, Peng G, Demir S. Multiscale modeling of biomedical, biological, and behavioral systems (Part 1). IEEE Eng Med Biol Mag. 2009; 28(2):12-13.

46. White R, Peng G, Demir S. Multiscale modeling of biomedical, biological, and behavioral systems (Part 2). IEEE Eng Med Biol Mag. 2009;28(3):8-9.

47. Mental Status Exam (MSE). Available from: http://en.wikipedia.org/ wiki/Mental_status_examination. Accessed Sept 1, 2010.

48. Using MRI and PET to diagnose mental illness. Available from: http:// www.scientificblogging.com/print/3081. Accessed Sept 1, 2010.

49. Dasgupta P. Valuation and Evaluation: Measuring the Quality of Life and Evaluating Policy. World Bank's annual World Development Report. Cambridge: University of Cambridge; 2000.

50. The Health Triangle. Available from: http://www.ehow.com/ about_5046294_health-triangle.html. Accessed Sept 1, 2010.

51. Glass L, Mackey MC. From Clocks to Chaos - The rhythms of life. New Jersey: University Press; 1988.

52. Li TY, Yorke JA. Period three implies chaos. Am Math Mon. 1975; 82(10):985-992.

53. Gardner AJ, Evans JP. Mammalian membrane block to polyspermy: new insights into how mammalian eggs prevent fertilisation by multiple sperm. Reprod Fertil Dev. 2006;18(1-2):53-61.

54. Nesse RM, Williams GC. Evolution and the origins of disease. Scientific American. 1998 Nov:86-93.

55. The Medical Classic of Emperor Huang, 1982 ed. Beijing: People's Medical Publishing House; 1995.

56. Nutton V. Ancient Medicine. Oxford: Routledge Publishing House; 2005.

57. Chinese Classical Books. Available from: http://guji.artx.cn/article/9638. html. Accessed Sept 1, 2010.

58. Huang H. Variorum and collective collation of Ho-Kuan-tzu. Beijing: Zhonghua Book Company; 2005.

59. Lemonick MD. Depression: the power of mood. Time. 2003 Jan 20: 36-41.

60. Kalb C. Faith and Healing - Can religion improve health? Newsweek. 2003 Nov 17:40-46.

61. Sloan RP, Bagiella E, Powell T. Religion, spirituality, and medicine. Lancet. 1999;353(9153):664-667.

62. Churchill LR. The dangers of looking for the health benefits of religion. Lancet. 2007;369(9572):1509-1510.

63. 2010 mHealth Summit. Available from: http://www.mhealthsummit. org/. Accessed Sept 1, 2010.
Journal of Multidisciplinary Healthcare

\section{Publish your work in this journal}

The Journal of Multidisciplinary Healthcare is an international, peerreviewed open-access journal that aims to represent and publish research in healthcare areas delivered by practitioners of different disciplines. This includes studies and reviews conducted by multidisciplinary teams as well as research which evaluates the results or conduct of such teams or

\section{Dovepress}

healthcare processes in general. The journal covers a wide range of areas and welcomes submission from practitioners at all levels, from all over the world. The manuscript management system is completely online and includes a very quick and fair peer-review system. Visit http://www.dovepress.com/testimonials.php to read real quotes from published authors. 